\title{
Variability in Primary Productivity associated with Arctic sea-ice melt recorded in Crustose Coralline Algae
}

P.T.W. CHAN ${ }^{1 *}$, J. HALFAR ${ }^{2}$, Z. ZAJACZ ${ }^{3}$, B.R. SCHÖNE ${ }^{4}$, C. ANDERSSON-DAHL ${ }^{5}$, AND E. JANSEN ${ }^{6}$

${ }^{1}$ University of Bergen, Bergen 5007, Norway. (*correspondence: phoebe.chan@uib.no)

${ }^{2}$ University of Toronto, Mississauga L5L 1C6, Canada. (jochen.halfar@utoronto.ca)

${ }^{3}$ University of Geneva, Geneva 1205, Switzerland. (zoltan.zajacz@unige.ch)

${ }^{4}$ University of Mainz, Mainz 55128, Germany. (schoeneb@uni-mainz.de)

${ }^{5}$ Norwegian Research Centre, Bergen 5008, Norway. (caan@ norceresearch.no)

${ }^{6}$ University of Bergen, Bergen 5007, Norway. (eystein.jansen@uib.no)

Accelerated warming and melting of Arctic sea-ice has been associated with significant increases in phytoplankton productivity in recent years. However, instrumental observations are both spatially and temporally limited in the cold and remote Arctic and Subarctic seas. Coldwater crustose coralline algae (CCA) have thus become an increasingly valuable archive for paleoclimate research in mid-to-high latitude oceans. These shallow marine calcareous plants are long-lived on the timescale of centuries and they secrete a high-Mg calcite skeleton that produces annual growth bands, enabling the precise calendar dating and geochemical sampling of hard tissue.

Utilizing a multiproxy approach, we highlight the current high-resolution isotopic and trace element proxies used in Clathromorphum spp. coralline algae to reconstruct variability in arctic sea-ice cover and productivity. Growth increment widths and magnesium-to-calcium $(\mathrm{Mg} / \mathrm{Ca})$ ratios in CCA are sensitive to changes in both temperature and solar radiation, and show a strong inverse relationship to Arctic sea-ice cover based on satellite and sea-ice chart data. In addition, barium-to-calcium ratios $(\mathrm{Ba} / \mathrm{Ca})$ and carbon isotopes $\left(\delta^{13} \mathrm{C}\right)$ measured in coralline algae demonstrate significant correlations to both instrumental, satellite, and proxy records of sea-ice variability and primary productivity. The combination of trace element and isotope proxies in CCA provides a robust and timely understanding of how Arctic sea-ice impacts phytoplankton productivity, especially as warming and freshening is projected to intensify over the coming century. 